University of Nebraska - Lincoln

DigitalCommons@University of Nebraska - Lincoln

$10-2010$

\title{
Efficient synthesis and conformational investigations of cis-pentacenediols
}

\author{
Jinyue Jiang \\ University of Nebraska - Lincoln, jjiang2@unl.edu \\ Charles E. Schiaffo \\ University of Nebraska-Lincoln \\ Chris P. Schwartz \\ University of Nebraska-Lincoln \\ Yong Pei \\ University of Nebraska-Lincoln \\ Joseph J. Dumais \\ University of Nebraska-Lincoln \\ See next page for additional authors
}

Follow this and additional works at: https://digitalcommons.unl.edu/chemistrydussault

Part of the Chemistry Commons

Jiang, Jinyue; Schiaffo, Charles E.; Schwartz, Chris P.; Pei, Yong; Dumais, Joseph J.; Zeng, Xiao Cheng; Dussault, Patrick; and Tan, Li, "Efficient synthesis and conformational investigations of cis-pentacenediols" (2010). Patrick Dussault Publications. 18.

https://digitalcommons.unl.edu/chemistrydussault/18

This Article is brought to you for free and open access by the Published Research - Department of Chemistry at DigitalCommons@University of Nebraska - Lincoln. It has been accepted for inclusion in Patrick Dussault Publications by an authorized administrator of DigitalCommons@University of Nebraska - Lincoln. 


\section{Authors}

Jinyue Jiang, Charles E. Schiaffo, Chris P. Schwartz, Yong Pei, Joseph J. Dumais, Xiao Cheng Zeng,

Patrick Dussault, and Li Tan 


\title{
Efficient synthesis and conformational investigations of cis-pentacenediols
}

\author{
Jinyue Jiang, ${ }^{1}$ Charles E. Schiaffo, ${ }^{2}$ Chris P. Schwartz, ${ }^{2}$ Yong Pei,,${ }^{2}$ Joseph J. Dumais, ${ }^{2}$ \\ Xiao Cheng Zeng, ${ }^{2}$ Patrick H. Dussault, ${ }^{2}$ and Li Tan ${ }^{1}$
}

\author{
1. Department of Engineering Mechanics and Nebraska Center for Materials and Nanoscience, \\ University of Nebraska-Lincoln, Lincoln, NE 68588 \\ 2. Department of Chemistry, University of Nebraska-Lincoln, Lincoln, NE 68588 \\ Corresponding author - Li Tan, tel 402 472-4018, fax 402 472-8292, email 1tan4@unl.edu
}

\begin{abstract}
Diisobutylaluminum hydride is utilized to reduce pentacene-6,13-diones to the corresponding diols, useful precursors to functionalized pentacenes. This pathway is mild and efficient, and produces the cis-diols as major products. Further, we found the cis-diols adopt endo conformation, which cannot flip to the exo conformation under ambient conditions. Due to the cis and endo orientation, the cis-diols can be potential bidentates in catalysis, molecular propellers, and optoelectronic devices.
\end{abstract}

Keywords: Pentacene, Pentacenediol, Reduction of pentacenedione, Diisobutylaluminum hydride, Low-temperature NMR

Pentacene, the work horse in the field of organic field-effect transistors, is prepared from pentacene-6,13-dione via two pathways, either a one-step reaction with $\mathrm{Al}-\mathrm{Hg}$ amalgam, ${ }^{1,2}$ or by a stepwise conversion involving metal hydride reduction to 6,13-dihydropentacene-6,13-diol, followed by aromatization with tin chloride. ${ }^{3,4}$ Because of the health and environmental risks involved in the use of mercury, the former methodology has almost been phased out in industry, and is only occasionally executed in research labs. Compared with the former, the latter proceeds in a reproducible and clean fashion, and hence is dominant in the literatures. Metal hydrides, such as, $\mathrm{KBH}_{4}, \mathrm{NaBH}_{4}$, and $\mathrm{LiAlH}_{4}$, are able to deliver good results with pentacene-6,13-dione, ${ }^{3-5}$ however, they fail to reduce 2,3-dibromopentacene-6,13-dione, a useful intermediate in the synthesis of functionalized pentacenes. ${ }^{2,6}$ Herein we report diisobutylaluminum hydride (DIBAH) as a useful reagent for reduction of pentacenediones. Easily handled DIBAH is mild, and very useful in reducing carbonyl functionality, ${ }^{7-10}$ but its application with pentacene-6,13-dione has not been investigated so far. As discussed later, this methodology delivers the cis-diol as the major product, and therefore the cis-diol can be separated as a pure isomer (Scheme 1). In view of the two hydroxyls' specific orientation and the two flanking naphthyl moieties, we envision the cis-diols as useful bidentates to coordinate with suitable centers, and thus to have potential applications in catalysis, molecular propellers, and/or optoelectronic devices.

Our efforts to reduce 2,3-dibromopentacene-6,13-dione with metal hydride revealed that neither $\mathrm{NaBH}_{4}$ nor $\mathrm{LiAlH}_{4}$ was effective, even at elevated temperatures, but DIBAH readily realized this. ${ }^{11,12} \mathrm{We}$ attribute this to the excellent solubil- ity of DIBAH. In contrast, it has been reported that a successful reduction of the unsaturated pentacene-6,13-dione needs a stepwise addition of $\mathrm{KBH}_{4}$ over a period of 10 -days. ${ }^{3}$ Very likely, the metal hydrides suffered because of their poor solubility in the system.

In order to better understand the reactivity of DIBAH within this system, we further investigated the reduction of the unsubstituted pentacene-6,13-dione as a model substrate. Compared with literatures, ${ }^{[3-5]}$ our procedure with DIBAH offers conveniences in handling and stoichiometric addition. Furthermore, it is mild and efficient-in less than 2 $\mathrm{h}$, and at $\mathrm{rt}$, the reaction is complete, producing an approximately 2:1 mixture of the cis and trans isomers of 6,13-dihydropentacene-6,13-diol with good yield (the major product was assigned based on a previous report). ${ }^{3}$ When $\mathrm{NaBH}_{4}$ or $\mathrm{LiAlH}_{4}$ was applied, the trans isomer was reported as the major product. ${ }^{4,5} \mathrm{~A}$ density functional theory (DFT) analysis of the energy states during the reduction, summarized in Figure 1, provides a rationale for the observed selectivity. ${ }^{13-16}$ The reduction of the first carbonyl group proceeds via a hydrideion transfer from the reducing agent DIBAH to the diketone A. First the intermediate $B$ is formed from an acid-base reaction between the unshared electron pair on oxygen of A with the aluminum atom of DIBAH, and then the intermediate D forms after transfer of a hydride-ion from DIBAH to the carbon atom of the carbonyl group. Our theoretical calculation suggests that the first reaction from $A$ to $B$ is a downhill one with no transition state, whereas in the second reaction from $B$ to $\mathrm{D}$, a transition state $\mathrm{C}$ exists. Similarly the second carbonyl group is reduced following the same pathway. The product selectivity occurs at the second transition state F, but its ori- 


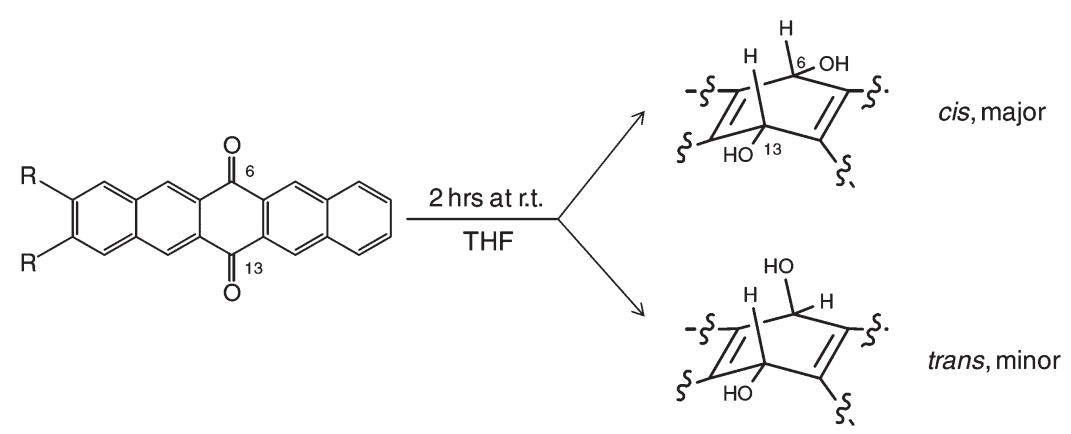

Scheme 1. Conversion of pentacene-6,13-dione to 6,13-dihydropentacene-6,13-diol with diisobutylaluminum hydride. $\mathrm{R}=\mathrm{H}$ or $\mathrm{Br}$.

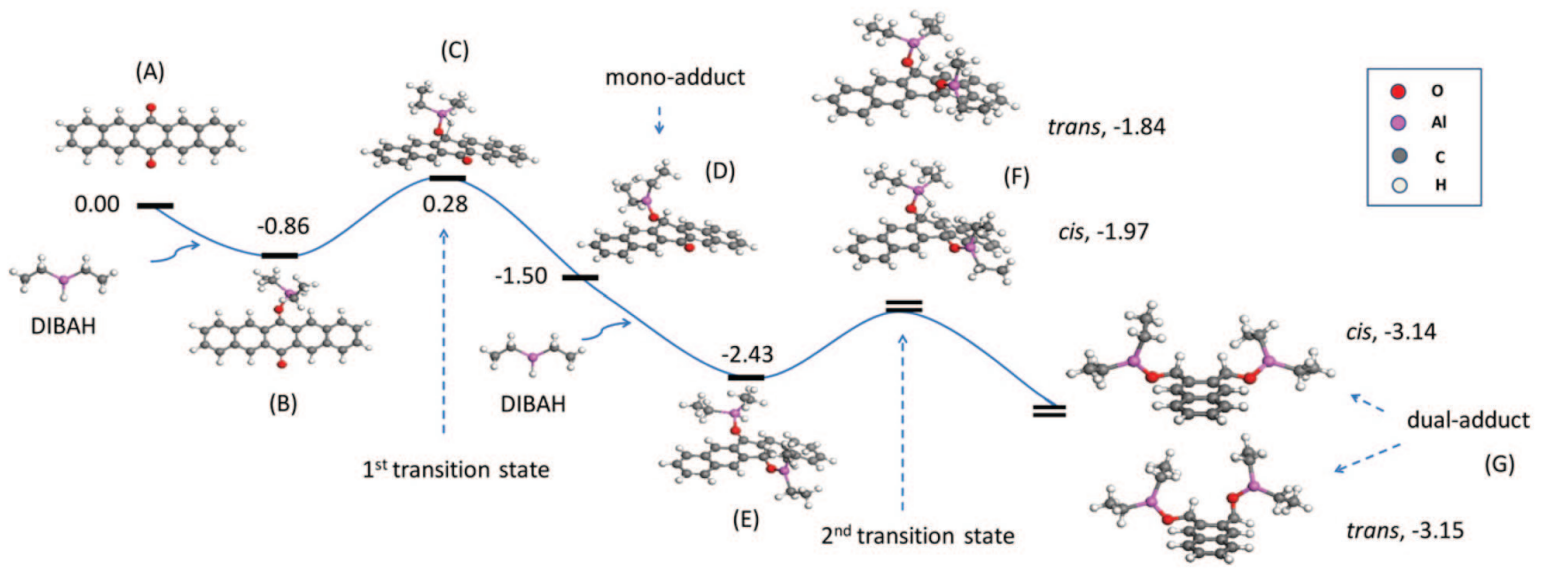

Figure 1. Calculated energy states (energy is in eV) from pentacene-6,13-dione to the dual-adducts before hydrolysis. It suggests that in the second transition state, the activation energy for the cis isomer is $0.13 \mathrm{eV}$ lower than that for the trans one. Such a difference results in the cis isomer being a dominant product. (A) the substrate; (B) the complex between the substrate and a single DIBAH; (C) the 1st transition state; (D) the mono-adduct; (E) the complex between the mono-adduct and another DIBAH; $(\mathrm{F})$ the 2nd transition states for the trans and cis isomers, respectively; and $(\mathrm{G})$ the two dual-adducts before hydrolysis.

gin can date back to the mono-adduct $\mathrm{D}$, which adopts a puckered conformation along its 6 and 13 carbons with a dihedral angle being $160^{\circ}$. As a result of this conformation, the second hydride is delivered from the exo face to furnish the endo alcohol. In fact, our calculation suggests an energy difference of $0.13 \mathrm{eV}$ between the second transition states. Hence the cis isomer is a dominant product.

Our careful assignment of the ${ }^{1} \mathrm{H}$ NMR spectra of 6,13-dihydropentacene-6,13-diol leads to another finding that differs from a previous report. ${ }^{4}$ The cis-diol is expected to have five peaks in the ${ }^{1} \mathrm{H}$ NMR spectrum: three signals for aromatic hydrogens, one for the carbinol $\mathrm{CH}$, and another one for the hydroxyl groups. And the expected relative integration ratio should be $4: 4: 4: 2: 2$. In various deuterated solvents such as THF- $d_{8}, \mathrm{CDCl}_{3}$, acetone- $d_{6}$, and DMSO- $d_{6}$, we found that the three aromatic hydrogen peaks are in good agreement with the literature, but a difference arose in the assignments for the carbinol $\mathrm{CH}$ and the $\mathrm{OH}$ groups. For example in acetone- $d_{6}$, these two very peaks for cis isomer are at 5.91 and $5.67 \mathrm{ppm}$, respectively. As shown in Figure 2a, they are coupled with ${ }^{3} J_{\mathrm{H}}$ $=\sim 7.0 \mathrm{~Hz} . \mathrm{A}{ }^{1} \mathrm{H}-{ }^{13} \mathrm{C}$ HSQC experiment demonstrated that the hydrogen at $5.91 \mathrm{ppm}$ is directly bonded to a carbon, whereas the peak at $5.67 \mathrm{ppm}$ is missing from the HSQC due to its lack of attachment to carbon. Upon deuterium exchange in acetone- $d_{6}$, the peak at $5.67 \mathrm{ppm}$ disappeared completely, and at the same time, the peak at $5.91 \mathrm{ppm}$ collapsed to a singlet, indicating that the hydrogen at $5.67 \mathrm{ppm}$ is active and labile to deuterium exchange, and is therefore assigned as the hydroxylic hydrogen. The 2D NMR plus the deuterium exchange experiment unambiguously led us to assign the peak at 5.91 ppm to the 6,13-CH hydrogen, and the peak at $5.67 \mathrm{ppm}$ to the hydroxylic hydrogen. A previous report for cis-pentacenediol has described the H6 and $\mathrm{H} 13$ as displaying discrete peaks in ${ }^{1} \mathrm{H}$ NMR, separated by at least 0.1 ppm. ${ }^{4}$

As shown in Figure 1, the cis isomer is predicted to adopt the endo conformation. The disparity between our observations and that reported led us to investigate whether the pentacenediol could exist as both endo- and exo-conformers and how easily these could interconvert. To answer these questions, we performed a series of NMR experiments on the cis isomer at varying temperatures at $600 \mathrm{MHz}$. In ${ }^{1} \mathrm{H}$ NMR, all peaks kept their chemical shift with varying temperatures, except one, the hydroxylic hydrogen, which migrated dramatically from 5.67 ppm at $298 \mathrm{~K}$ to $6.44 \mathrm{ppm}$ at $205 \mathrm{~K}$ (Figure 3). However, no change was observed in the ${ }^{13} \mathrm{C}$ spectra over the same temperature range, suggesting the ${ }^{1} \mathrm{H}$ signal change for the $\mathrm{OH}$ is not associated with major conformational changes in the dihydropentacene skeleton. We suspect the change is probably due to the temperature-dependent geometry of hydrogen-bonding. ${ }^{17}$ As we did not observe the $\mathrm{CH}$ peak resolving into two peaks at a low temperature of $205 \mathrm{~K}$, it could be either that at 205 $\mathrm{K}$, the isomeric flip is too fast for the NMR window to detect or that only endocis isomer exists and no flipping occurs at all. Our verdict favors the latter one. As shown in Scheme 1, the endocis isomer can be viewed as a boat conformation of cyclohexane with $4 \mathrm{sp} 2$ carbons on sides. Consequently, flipping between exo and endo conformations, if any, probably involves extreme energy. Collectively, our results suggest that the 

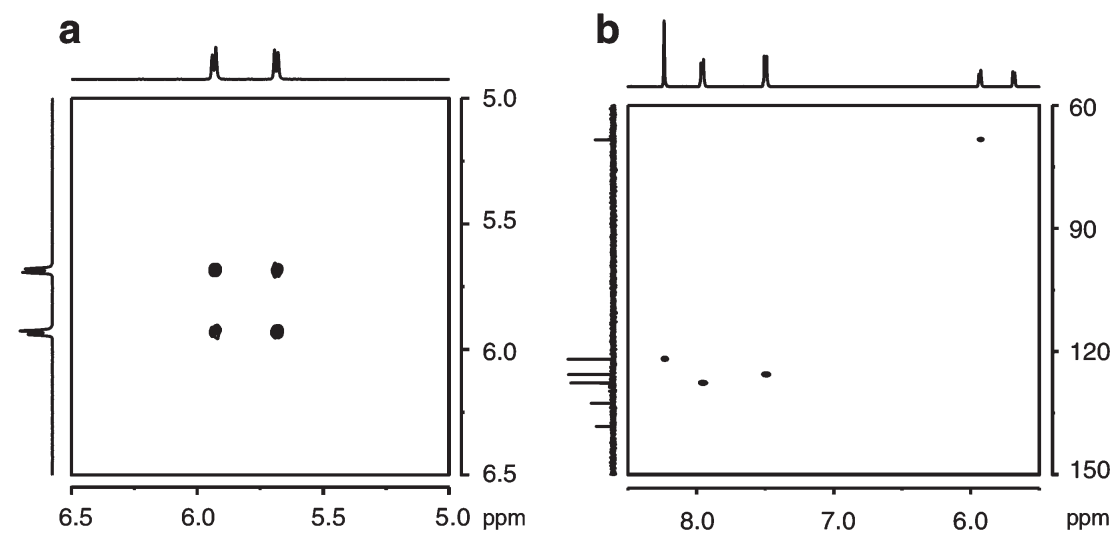

Figure 2. 2D NMR spectra of cis-6,13-dihydropentacene-6,13-diol in acetone- $d 6$. (a) ${ }^{1} \mathrm{H}-{ }^{1} \mathrm{H}$ COSY in the region of $5.0-6.5 \mathrm{ppm}$, indicating that the peaks at 5.67 and $5.91 \mathrm{ppm}$ couple to each other with ${ }^{3} \mathrm{~J}_{\mathrm{H}}=\sim 7.0 \mathrm{~Hz}$. (b) ${ }^{1} \mathrm{H}-{ }^{13} \mathrm{C}$ HSQC indicates that the proton at $5.91 \mathrm{ppm}$ is directly bonded to a carbon, whereas the one at $5.67 \mathrm{ppm}$ is not. Plus the fact that the proton at $5.67 \mathrm{ppm}$ is labile to deuterium exchange, the peak at $5.67 \mathrm{ppm}$ is assigned to the hydroxylic proton. For clarity, ${ }^{1} \mathrm{H}$ NMR at $x$-axis is shown from 5.5 to $8.5 \mathrm{ppm}$ and ${ }^{13} \mathrm{C}$ NMR at $y$-axis, from 60 to $150 \mathrm{ppm}$.

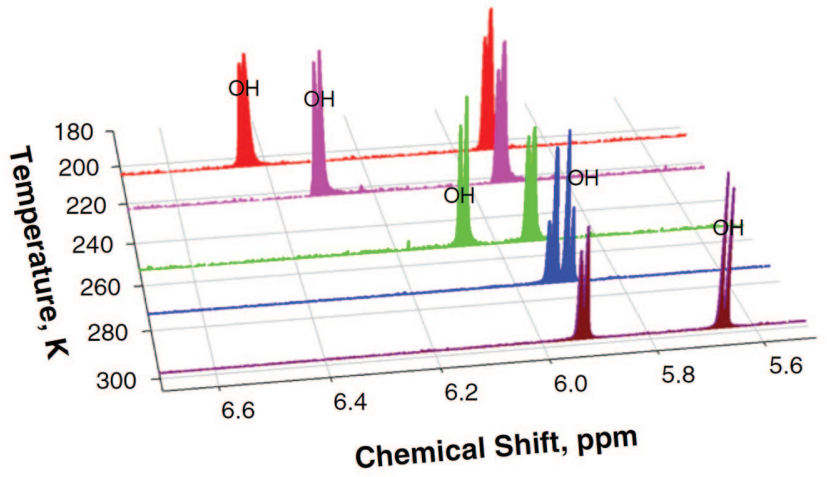

Figure 3. NMR spectra of cis-6,13-dihydropentacene-6,13-diol in acetone- $d_{6}$ between 205 and $293 \mathrm{~K}$ (for clarity, only 5.5-6.7 ppm is displayed). In contrast to the immobile peak at $5.91 \mathrm{ppm}$, the hydroxylic hydrogen peak migrated dramatically from $5.67 \mathrm{ppm}$ at $298 \mathrm{~K}$ to $6.44 \mathrm{ppm}$ at $205 \mathrm{~K}$. The symbol OH highlights the peaks of hydroxylic hydrogen, and the normal direction stands for the normalized intensity.

DIBAH reduction of pentacenediones selectively furnishes the cis-6,13-diol as a single major conformer displaying only one carbinol $\mathrm{CH}$ peak in ${ }^{1} \mathrm{H}$ NMR.

In summary, DIBAH is effective at converting pentacene6,13-diones into 6,13-dihydropentacene-6,13-diols. This transformation proceeds with good selectivity for production of the cis isomer, which can be isolated in pure form. Considering the specific orientation of hydroxyl functionality and the two rigid conjugated flanks, we foresee that the cis-diol isomer will possibly find applications in catalysis, molecular propellers, and optoelectronic devices. This pathway is likely to be applicable as a means of reducing other functionalized pentacenediones, and we are now actively pursuing in that direction.

Acknowledgments - The authors gratefully acknowledge the partial financial support from the National Science Foundation (CMMI 0825905; Program Manager: Dr. Clark Cooper) and the Army Research Office (W911NF-08-1-0190; Program Manager: Dr. Dwight Woolard).

\section{References and notes}

1. V. Bruckner, A. K. Wilhelms, K. Kormendy, M. Meszaros, and J. Tomasz. Tetrahedron Lett., (1960), pp. 5-6.

2. T. Okamoto, M.L. Senatore, M.-M. Ling, A. B. Mallik, M. L. Tang, and Z. Bao. Adv. Mater., 19 (2007), pp. 3381-3384.

3. D. Sparfel, F. Gobert, and J. Rigaudy. Tetrahedron, 36 (1980), pp. 2225-2235.

4. N. Vets, M. Smet, and W. Dehaen. Tetrahedron Lett., 45 (2004), pp. 7287-7289.

5. K. Kobayashi, R. Shimaoka, M. Kawahata, M. Yamanaka, and K. Yamaguchi. Org. Lett., 8 (2006), pp. 2385-2388.

6. C. R. Swartz, S. R. Parkin, J. E. Bullock, J. E. Anthony, A. C. Mayer, and G. G. Malliaras. Org. Lett., 7 (2005), pp. 3163-3166.

7. M.-C. P. Yeh, Y.-C. Lee and T.-C. Young. Synthesis, 2006 (2006), pp. 3621-3624.

8. H. D. Dickson, S. C. Smith, and K. W. Hinkle. Tetrahedron Lett., 45 (2004), pp. 5597-5599.

9. R. S. Porto, M.L.A.A. Vasconcellos, E. Ventura, and F. Coelho. Synthesis, 2005 (2005), pp. 2297-2306.

10. N. M. Yoon and Y.S.T. Gyoung. J. Org. Chem., 50 (1985), pp. 2443-2450.

11. Synthesis of 6,13-dihydropentacene-6,13-diol: To a suspension of pentacene-6,13-dione $(308.3 \mathrm{mg}, 1 \mathrm{mmol})$ in anhydrous THF $(30 \mathrm{~mL})$ was added dropwise DIBAH in toluene $(1.5 \mathrm{M}, 2 \mathrm{~mL})$. The reaction mixture was then stirred at $\mathrm{rt}$ for $2 \mathrm{~h}$, followed by addition of saturated aqueous Rochelle's salt solution $(25 \mathrm{~mL})$. The resulting mixture was stirred at $\mathrm{rt}$ for another $2 \mathrm{~h}$. Filtration and copious washing with distilled water and $\mathrm{CH}_{2} \mathrm{Cl}_{2}$ gave an orange solid (250 $\mathrm{mg}, 80 \%)$. NMR confirmed this orange solid is a mixture of cis-6,13-dihydropentacene-6,13-diol and trans-6,13-dihydropentacene-6,13-diol (cis/trans, 2:1). HRFAB: calcd for $\mathrm{C}_{22} \mathrm{H}_{16} \mathrm{O}_{2}, 312.1151$; found 312.1140 .

Careful purification of this mixture one time with column chromatography (eluent: Hex/EtOAc, 4:1) resulted in pure cis-6,13-dihydropentacene-6,13-diol (75 mg, 24\%). Mp, $230{ }^{\circ} \mathrm{C}$ (decomp.). ${ }^{1} \mathrm{H}$ NMR $\left(400 \mathrm{MHz}\right.$, acetone- $\left.d_{6}\right): 8.22$ $(4 \mathrm{H}, \mathrm{s}), 7.94(4 \mathrm{H}, \mathrm{m}), 7.48(4 \mathrm{H}, \mathrm{m}), 5.91(2 \mathrm{H}, \mathrm{d}, J=6.8 \mathrm{~Hz})$, $5.64(2 \mathrm{H}, \mathrm{d}, J=7.0 \mathrm{~Hz}) ;{ }^{13} \mathrm{C}$ NMR $\left(100 \mathrm{MHz}\right.$, acetone- $\left.d_{6}\right)$ : 139.2, 133.6, 128.7, 126.6, 122.9, 68.4; ${ }^{1} \mathrm{H}$ NMR (400 MHz, 
THF- $\left.d_{8}\right): 8.17(4 \mathrm{H}, \mathrm{s}), 7.87(4 \mathrm{H}, \mathrm{m}), 7.40(4 \mathrm{H}, \mathrm{m}), 5.77(2 \mathrm{H}$, $\mathrm{d}, J=7.5 \mathrm{~Hz}), 5.59(2 \mathrm{H}, \mathrm{d}, J=7.8 \mathrm{~Hz}) ;{ }^{13} \mathrm{C} \mathrm{NMR}(100 \mathrm{MHz}$, THF- $\left.d_{8}\right): 139.4,133.7,128.5,126.2,122.4,69.2 .{ }^{1} \mathrm{H}$ NMR $(400$ $\left.\mathrm{MHz} \mathrm{CDCl}_{3}\right): 8.08(4 \mathrm{H}, \mathrm{s}), 7.90(4 \mathrm{H}, \mathrm{m}), 7.53(4 \mathrm{H}, \mathrm{m}), 5.90$ $(2 \mathrm{H}, \mathrm{d}, J=7.1 \mathrm{~Hz}), 3.30(2 \mathrm{H}, \mathrm{d}, J=7.1 \mathrm{~Hz})$; HRFAB: calcd for $\mathrm{C}_{22} \mathrm{H}_{16} \mathrm{O}_{2}, 312.1151$; found 312.1165.

Trans-6,13-dihydropentacene-6,13-diol: NMR spectra were obtained via spectrum subtraction. ${ }^{1} \mathrm{H}$ NMR (400 $\mathrm{MHz}$, acetone- $\left.d_{6}\right): 8.10(4 \mathrm{H}, \mathrm{s}), 7.89(4 \mathrm{H}, \mathrm{m}), 7.45(4 \mathrm{H}, \mathrm{m})$, $6.15(2 \mathrm{H}, \mathrm{m}), 5.08(2 \mathrm{H}, \mathrm{m}) ;{ }^{13} \mathrm{C}$ NMR (100 MHz, acetone- $\left.d_{6}\right)$ : 139.3, 133.8, 128.5, 126.7, 125.2, 70.5; ${ }^{1} \mathrm{H}$ NMR (400 MHz, $\left.\mathrm{CDCl}_{3}\right): 8.14(4 \mathrm{H}, \mathrm{s}), 7.91(4 \mathrm{H}, \mathrm{m}), 7.52(4 \mathrm{H}, \mathrm{m}), 6.22(2 \mathrm{H}, \mathrm{d}$, $J=5.8 \mathrm{~Hz}), 2.28(2 \mathrm{H}, \mathrm{d}, J=5.8 \mathrm{~Hz})$.

12. Synthesis of 2,3-dibromo-6,13-dihydropentacene-6,13-diol: 2,3-dibromopentacene-6,13-dione (116 mg, $0.25 \mathrm{mmol}$ ) was used to prepare the target molecule, following a similar procedure as described in Note 11. Filtration and copious washing with distilled water and $\mathrm{CH}_{2} \mathrm{Cl}_{2}$ gave an orange solid. The solid was stirred with THF $(20 \mathrm{~mL})$ and the resulting suspension was filtered. Addition of $\mathrm{CH}_{2} \mathrm{Cl}_{2}(20$ $\mathrm{mL}$ ) to this THF filtrate resulted in an orange solid (cis, 30 $\mathrm{mg}, 25 \%)$. Further chromatographic purification on the residue failed to separate the trans-isomer due to its very lim- ited solubility. ${ }^{1} \mathrm{H}$ NMR (400 MHz, THF- $\left.d_{8}\right): 8.31(2 \mathrm{H}, \mathrm{s})$, $8.17(\mathrm{~s}, 2 \mathrm{H}), 8.15(\mathrm{~s}, 2 \mathrm{H}), 7.88(\mathrm{~m}, 2 \mathrm{H}), 7.41(\mathrm{~m}, 2 \mathrm{H}), 5.77-$ $5.72(\mathrm{~m}, 4 \mathrm{H}) ;{ }^{13} \mathrm{C}$ NMR $\left(100 \mathrm{MHz}, \mathrm{THF}-d_{8}\right): 141.6,138.9$, 133.8, 133.5, 133.2, 128.6, 126.4, 122.5, 121.9, 121.5, 69.1, HRFAB: calcd for $\mathrm{C}_{22} \mathrm{H}_{14} \mathrm{Br}_{2} \mathrm{O}_{2}$, 467.9361; found 467.8355.

13. Experimental details in theoretical calculation: The reaction pathway is investigated using the density functional theory (DFT) method. The B3LYP exchange-correlation functional is used. The $\mathrm{C}, \mathrm{H}, \mathrm{Al}$, and $\mathrm{O}$ atoms are treated with the 6-31g $(\mathrm{d}, \mathrm{p})$ basis set. All minima and transition states are confirmed via harmonic vibrational frequency calculations. All calculations are performed using the GAUSSIAN 03 software package.

14. P. Hohenberg and W. Kohn. Phys. Rev., 136 (1964), p. B864.

15. W. Kohn and L. J. Sham. Phys. Rev., 140 (1965), p. A1133.

16. A. D. Becke. J. Chem. Phys., 98 (1993), pp. 5648-5652.

17. P. M. Tolstoy, N. S. Golubev, S. N. Smirnov, G. S. Denisov and H. H. Limbach. J. Am. Chem. Soc., 125 (2003), pp. 11710-11720.

Supplementary data follows. 


\title{
Supporting Information for:
}

\section{Efficient synthesis and conformational investigations of cis- pentacenediols}

\author{
Jinyue Jiang ${ }^{a}$, Charles E. Schiaffo ${ }^{b}$, Chris P. Schwartz ${ }^{b}$, Yong Pei ${ }^{b}$, Joseph J. Dumais ${ }^{b}$, Xiao Cheng \\ Zeng $^{b}$, Patrick H. Dussault ${ }^{b}$, Li $\operatorname{Tan}^{\mathrm{a} *}$ \\ ${ }^{a}$ Department of Engineering Mechanics and Nebraska Center for Materials and Nanoscience, \\ University of Nebraska, Lincoln, NE, 68588 \\ ${ }^{b}$ Department of Chemistry, University of Nebraska, Lincoln, NE, 68588 \\ Email: Itan4@unl.edu
}

Table of Contents

Spectral Data.

S2 -9 
Figure S1: ${ }^{1} \mathrm{HNMR}$ of cis-6,13-dihydropentacene-6,13-diol (400 MHz, acetone- $d_{6}$ ). The insert is the NMR after $\mathrm{D}_{2} \mathrm{O}$ exchange, where the hydroxylic hydrogen peak is absent.
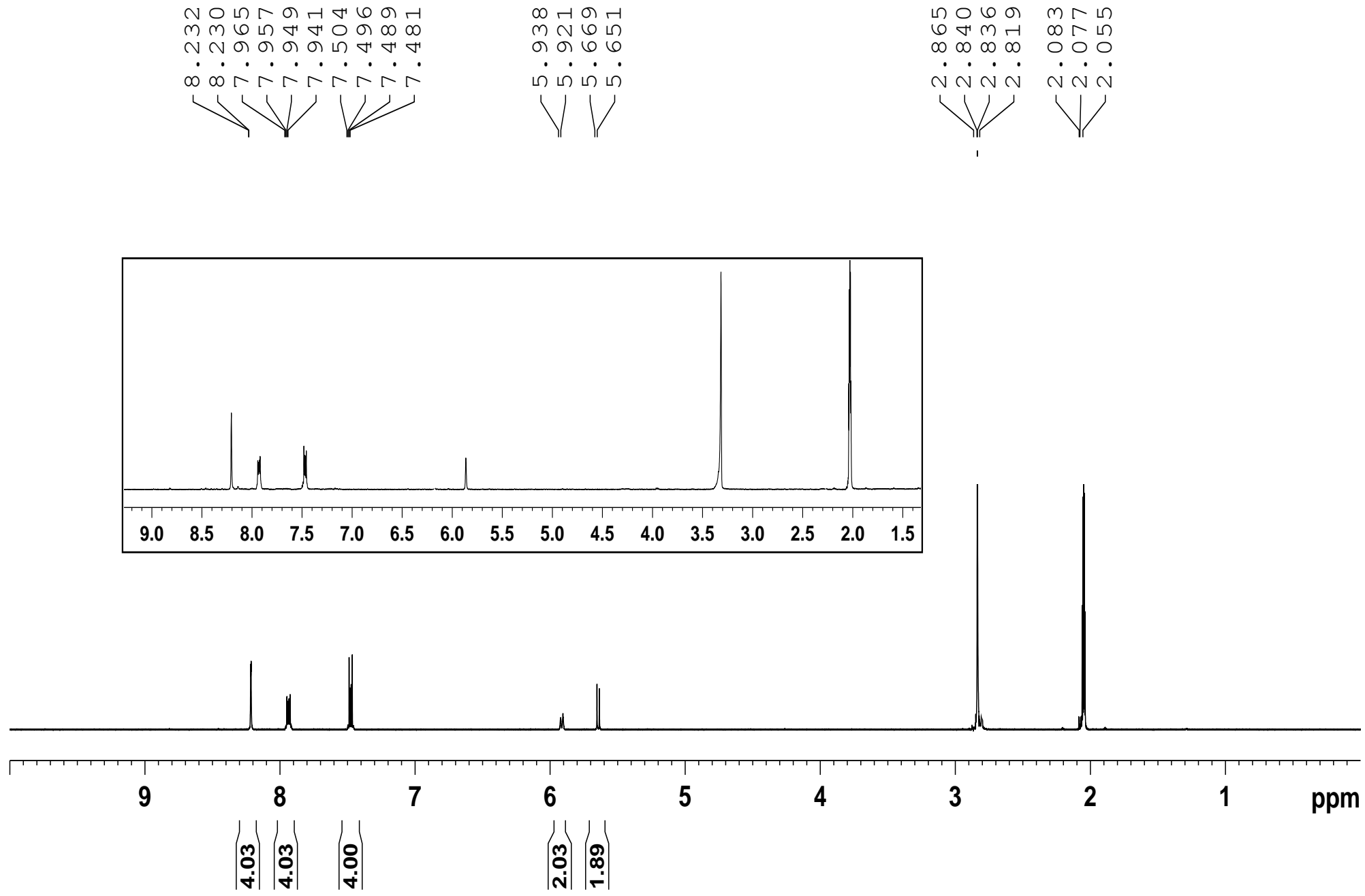
Figure S2: ${ }^{13}$ CNMR of cis-6,13-dihydropentacene-6,13-diol (100 MHz, acetone- $d_{6}$ )

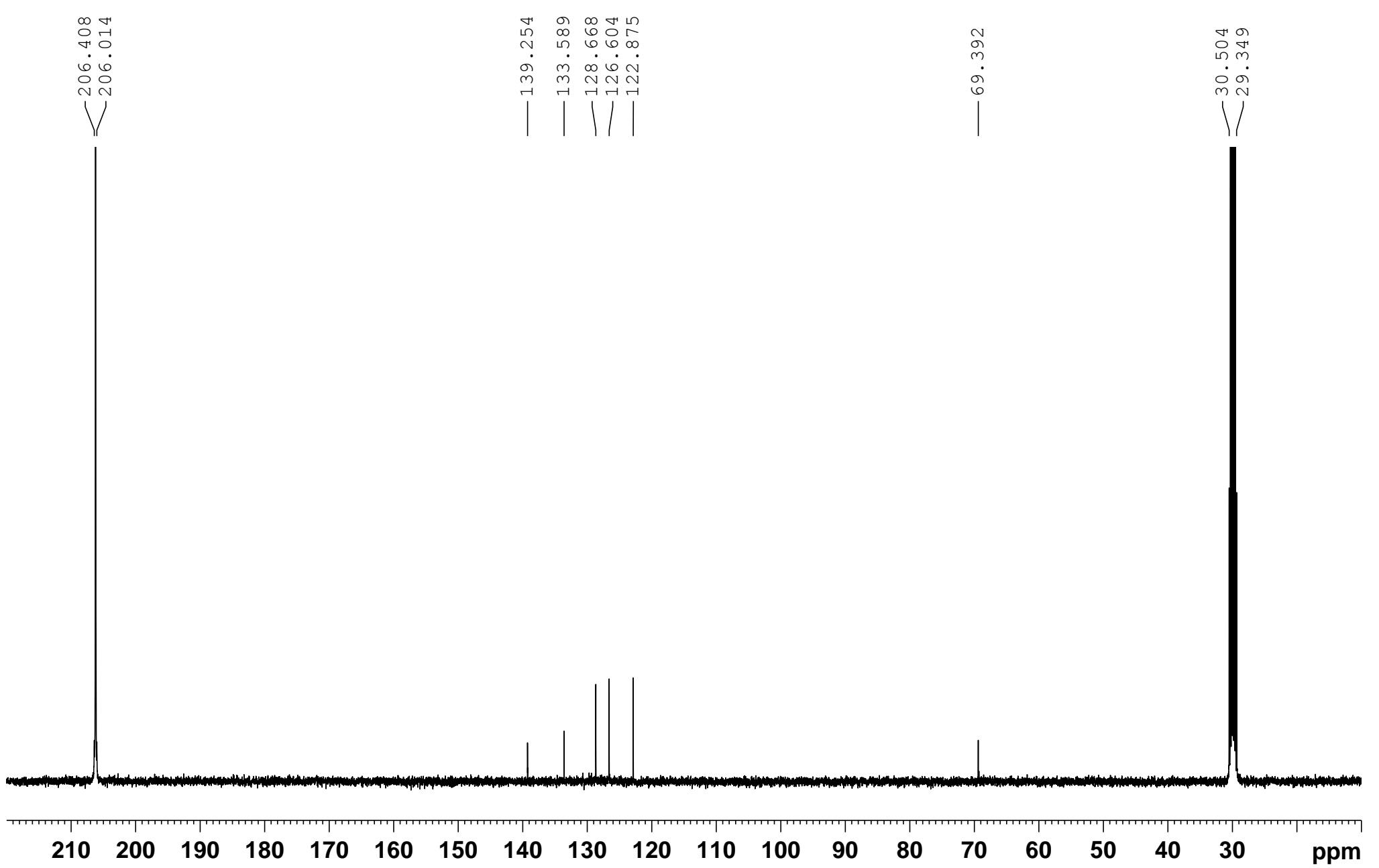


Figure S3: ${ }^{1} \mathrm{HNMR}$ of mixture of trans and cis-6,13-dihydropentacene-6,13-diol (400 MHz, acetone- $d_{6}$ ) after $\mathrm{D}_{2} \mathrm{O}$ exchange, where $\mathrm{OH}$ peak does not show up
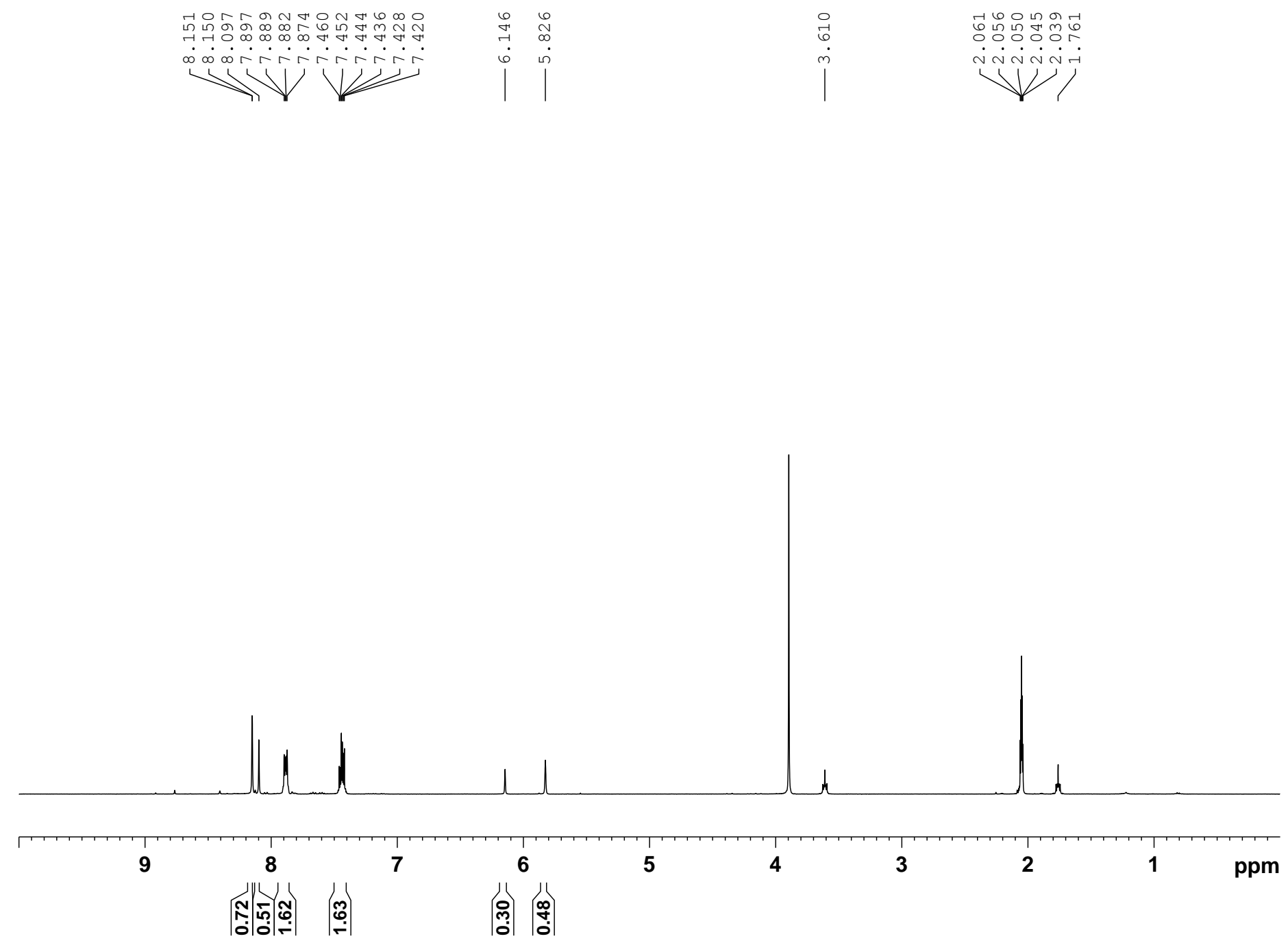
Figure S4: ${ }^{13} \mathrm{CNMR}$ of mixture of trans and cis-6,13-dihydropentacene-6,13-diol (100 MHz, acetone- $\left.d_{6}\right)$

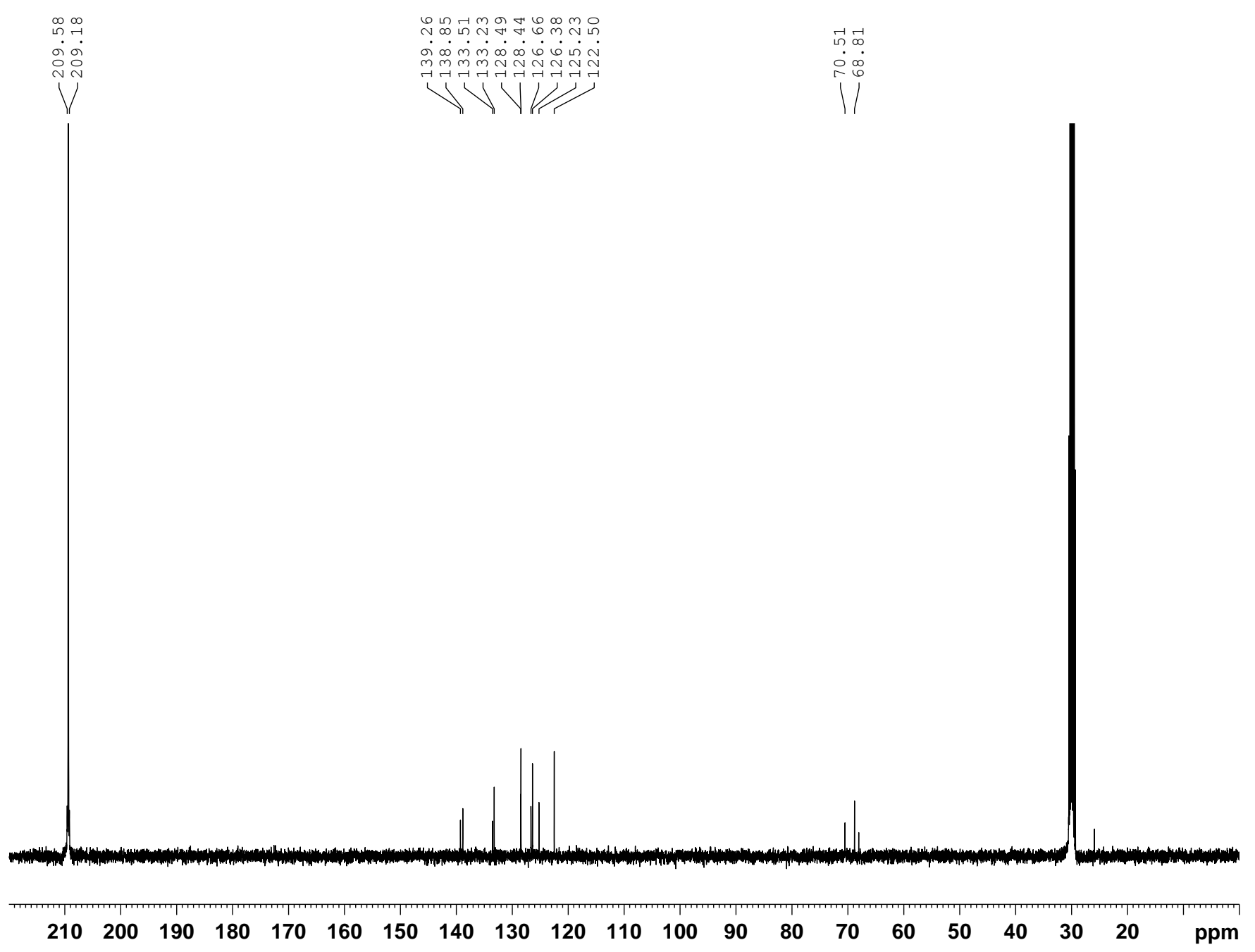


Figure S5: ${ }^{1} \mathrm{HNMR}$ of cis-2,3-dibromo-6,13-dihydropentacene-6,13-diol (400 MHz, THF- $d_{8}$ ). The insert is the NMR after $\mathrm{D}_{2} \mathrm{O}$ exchange, where the hydroxylic hydrogen peak is absent.

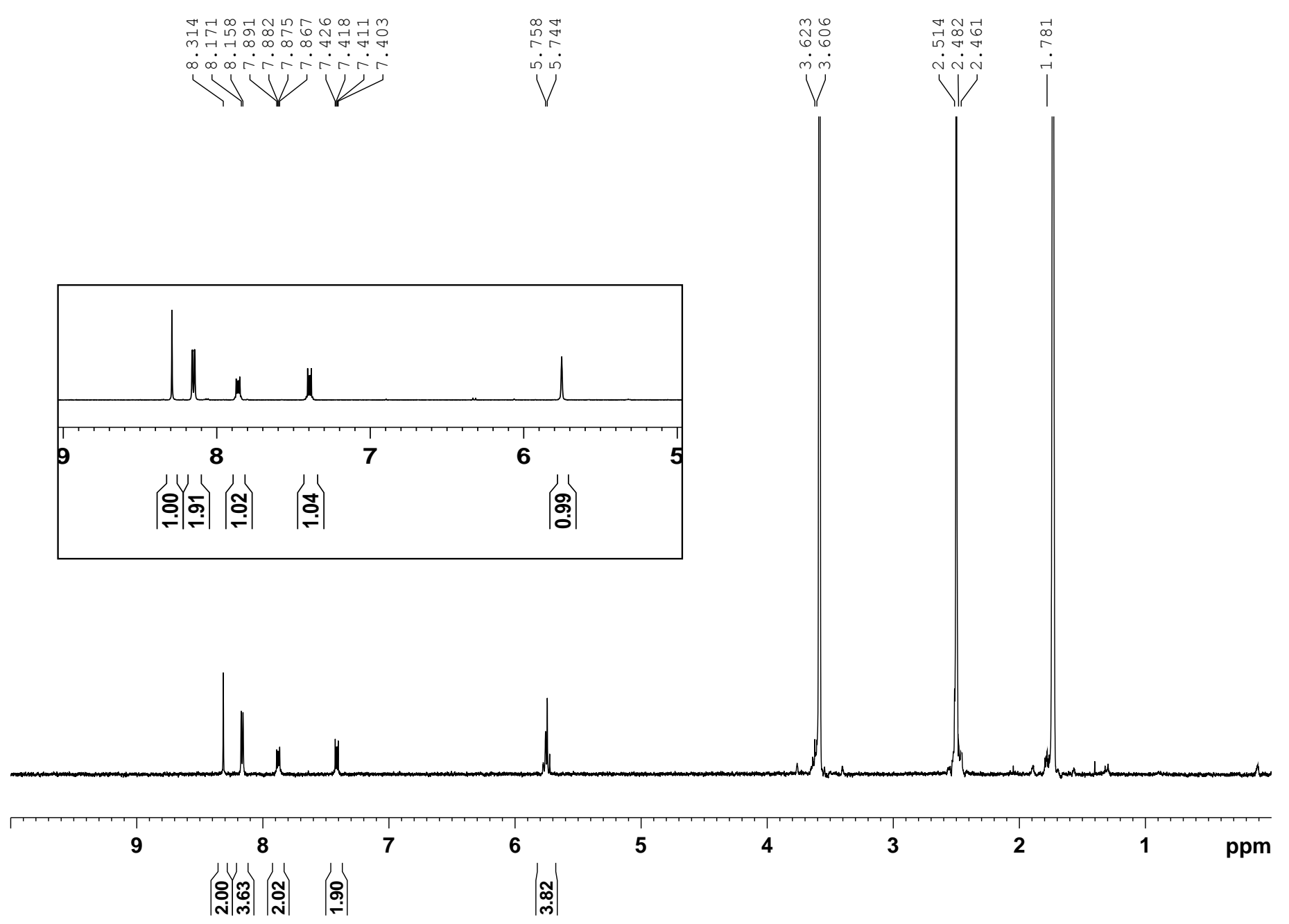


Figure S6: ${ }^{13} \mathrm{CNMR}$ of cis-2,3-dibromo-6,13-dihydropentacene-6,13-diol (100 MHz, THF- $d_{8}$ )

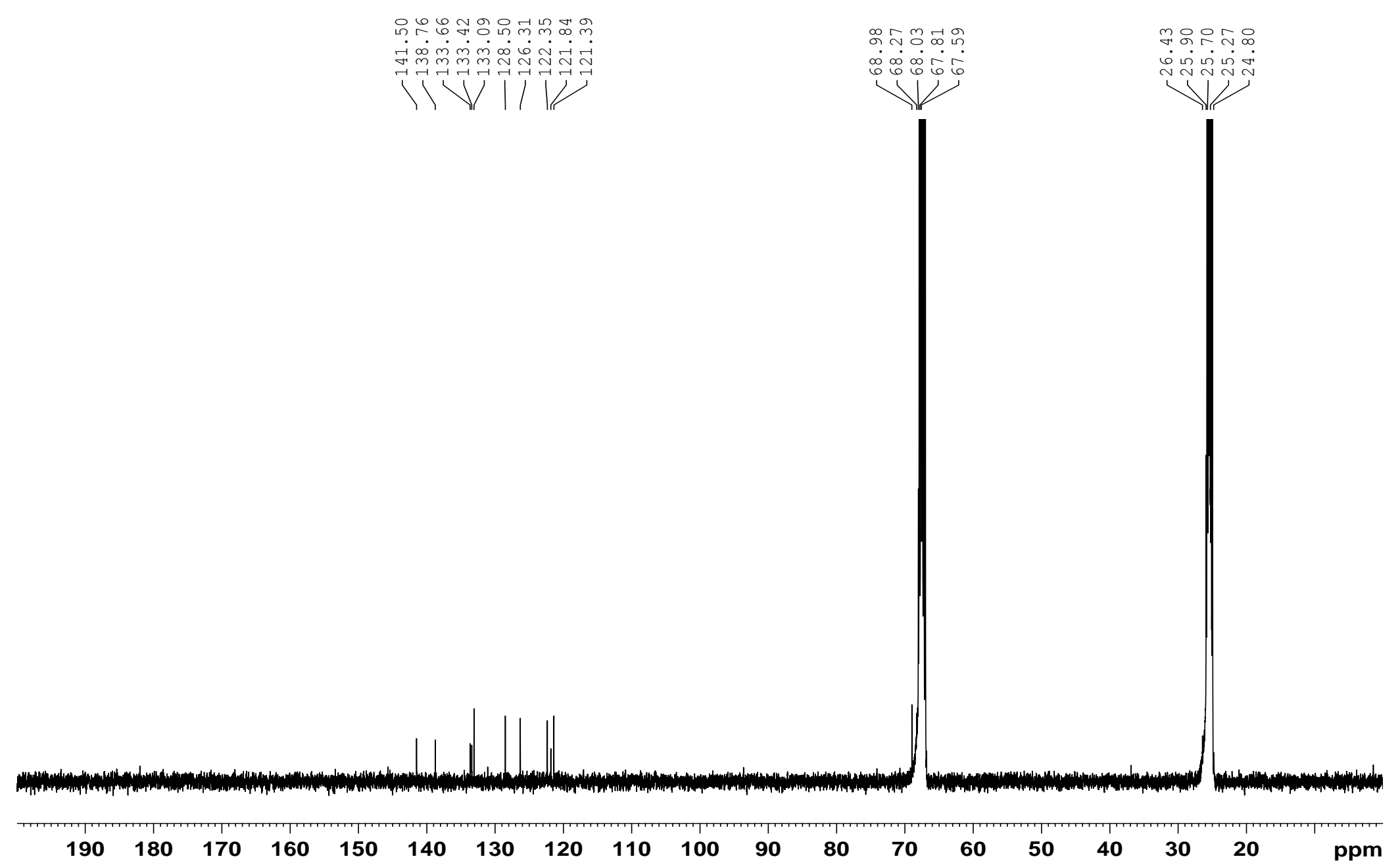

